\title{
LA LÍRICA IMPERSONAL DE LA URBE MODERNA: APROXIMACIÓN A BAUDELAIRE COMO TRADUCTOR DE EDGAR A. POE
}

\author{
Belén Piqueras Cabrerizo \\ Universidad Autónoma de Madrid
}

\begin{abstract}
RESUMEN: La obra de Edgar Allan Poe tuvo escaso impacto en la América del siglo XIX; este autor fue un cerebro solitario en una época en que su país estaba entregado a una frenética actividad material y a un desmesurado crecimiento económico. La metrópoli, el corazón de la civilización moderna, condena al hombre a una irrelevancia y a un anonimato que es devastador para los artistas y los intelectuales; pero Poe y Baudelaire encontraron en la ciudad y en sus masas informes un objeto artístico, y concibieron un método que escapaba de los códigos obsoletos de la figuración realista y revelaba de un modo eficaz la lírica moderna de los paisajes urbanos. El flaneur de Baudelaire está claramente inspirado en el "hombre de la multitud" de su admirado Poe, y refleja una sensibilidad moderna en el modo de concebir la figura del artista.
\end{abstract}

ABSTRACT: Poe's work had little impact in nineteenth century America, his own country being blindly devoted to industrial development and material progress. The metropolis, the core of modern civilization, condemns man to a condition of irrelevance and anonymity that is particularly devastating for artists and intellectuals; but both Poe and Baudelaire found in the city and its formless masses an artistic object, and conceived a method that eluded the obsolete codes of realist representation and efficiently revealed the modern lyricism of urban landscapes. Baudelaire's flaneur is clearly inspired in his admired Poe's "man of the crowds", and it reflects a modern sensitivity to the role of the artist.

PALABRAS CLAVE: E.A. Poe, C. Baudelaire, modernidad, ciudad, "art for art's sake".

KEYWORDS: E.A. Poe, C. Baudelaire, modernity, city, "art for art's sake”. 
Desde que Charles Baudelaire descubrió a Edgar Allan Poe a través de relatos ocasionalmente publicados en periódicos franceses hacia mediados del siglo XIX, su interés y admiración por el escritor americano no cesaron jamás. Según Charles Asselineau, amigo de Baudelaire, su entusiasmo llegaba a tal extremo que a menudo instigaba a sus interlocutores buscando intercambiar impresiones sobre su recién descubierto autor:

Quienquiera que, con o sin motivo, tuviese alguna reputación de conocedor de la literatura inglesa y americana era literalmente obligado por él [Baudelaire] a tratar de la cuestión. Agobiaba a los libreros extranjeros con encargos y demandas de información sobre las diversas ediciones de las obras de su autor, del cual algunos no habían oído hablar jamás. Fui más de una vez testigo de su cólera cuando alguno de ellos le confesaba no conocer ni al autor ni la obra, o le repetía cierta indicación que él ya sabía falsa. ¿Cómo era posible vivir sin conocer al detalle a Poe, su vida y sus obras? (Asselineau, 37-8)

En 1852 Baudelaire publica Edgar Allan Poe, sa vie et ses ouvrages, primera versión del futuro prólogo de sus Histoires Extraordinaires, traducción de relatos de Poe que aparece en 1856. Seguidamente trabaja en la traducción al francés de The Adventures of Gordon Pym, que publica dos años más tarde Le Moniteur. $\mathrm{Al}$ método habitualmente comprometido y escrupuloso de Baudelaire se une en esta ocasión su fascinación por la originalidad del autor americano, que le llevó a entrar en una comunicación cada vez más íntima con éste. Para Walter Benjamin, con la traducción de los cuentos de Poe, la obra de este autor penetró por entero en la del francés (Benjamin, 57).

En 1848 Baudelaire desarrolla en su ensayo de presentación de La revelación magnética, (Études sur Poe, en Baudelaire 1976) su famosa teoría de la sorpresa en torno a la figura de Edgar Allan Poe; allí afirma:

On a beaucoup parlé dans ces derniers temps d'Edgar Poe. Le fait est qu'il le mérite. Avec un volume de nouvelles, cette réputation a traversé les mers. Il a étonné, surtout étonné, plutôt qu'ému ou enthousiasmé. Il en est généralement de même de tous les romanciers qui ne marchent qu'appuyés sur une méthode créée par euxmêmes, et qui est la conséquence même de leur tempérament. (...) Tous ces gens, avec une volonté et une bonne foi infatigable, décalquent la nature, la pure nature.-Laquelle?-La leur. Aussi sont-ils généralement bien plus étonnants et originaux que les simples imaginatifs qui sont tout à fait indoués d'esprit philosophique, et qui entassent et alignent les événements sans les classer, et sans en expliquer le sens mystérieux. J'ai dit qu'ils étaient étonnants. Je dis plus: c'est qu'ils visent généralement à l'étonnant. (Baudelaire 1976, 247-8)

En este revelador pasaje se desvelan muchas de las claves del atractivo que Baudelaire encuentra en la figura y en la obra de Poe, y es que para él, el autor 
americano constituye el epítome del artista moderno. Por un lado, destaca en su narrativa un elemento de sorpresa, entendido como novedad $\mathrm{u}$ originalidad, en la línea de lo imaginario e incluso de lo misterioso; por otro, apunta a la aparición de nuevas formas poéticas, con esta referencia a un método de creación propio que, lejos de reflejar la naturaleza como realidad empírica, aporta a la obra un alto grado de subjetividad.

Baudelaire está hablando de una verdadera revolución artística, la que conlleva la transición de unos modos de representación clásica, mimesis de una realidad dada a priori, a la estética de la intuición y de la imaginación, con el filtro del artista traduciendo siempre lo invisible y lo impalpable. Y no es que el artista se complazca en la evocación de su "yo", sino que éste se proyecta sutilmente en la construcción del "paisaje interior" de la propia obra; el "yo" poético debe situarse en la totalidad trascendente del lenguaje.

Pero mientras la obra de Poe estaba despertando una gran curiosidad y admiración en Europa, sobre todo en Francia y en Inglaterra, no sucedía lo mismo en su tierra natal, donde cuanto menos era ignorada, si no denostada y menospreciada. Así, mientras que en 1846 la Revue des Deux Mondes publica un detallado y elogioso estudio de sus cuentos, The North American Review los califica ese mismo año como "basura" (trash) (en Walker I.M., 205-219 y 266-268). En la brillante reconstrucción de la tradición americana que William Carlos Williams lleva a cabo en su influyente obra In the American Grain (1925), Williams sugiere que los americanos no estaban preparados para asimilar la modernidad de Poe, -una modernidad que, según el crítico, es esencialmente americana-, lo que sí sucedió en Francia -gracias, sobre todo, a Baudelaire:

Poe's work strikes by its scrupulous originality, not "originality" in the bastard sense, but in its legitimate sense of solidity which goes back to the ground, a conviction that he can judge within himself. These things the French were ready to perceive and quick to use to their advantage: a new point from which to readjust the trigonometric measurements of literary form. (Williams, 216)

Y es que, según Baudelaire, América estaba ciegamente entregada a su desmesurado crecimiento económico: orgulloso de su desarrollo material, Los Estados Unidos está convencido de que se va a comer el mundo, y con su abrumadora fe en la omnipotencia de la industria, hace de la actividad material una manía nacional, dejando poco espacio para lo no terrenal. Con su apego por lo inmutable y lo eterno, Poe era allá un cerebro singularmente solitario. 
En sus "Notes novelles sur Edgar Poe" (1857), Baudelaire afirma:

Du sein d'un monde goulu, affamé de matérialités, Poe s'est élancé dans les rêves. Étouffé qu'il était par l'atmosphère américaine, il a écrit en tête d'Eureka: 'J'offre ce livre à ceux qui ont mis leur foi dans les rêves comme dans les seules réalités !' Il fut donc une admirable protestation; il la fut et il la fit à sa manière, in his own way. L'auteur qui, dans le Colloque entre Monos et Una, lâche à torrents son mépris et son dégoût sur la démocratie, le progrès et la civilisation, cet auteur est le même qui, pour enlever la crédulité, pou ravir la badauderie des siens, a le plus énergiquement posé la souveraineté humaine et le plus ingénieusement fabriqué les canards les plus flatteurs pour l'orgueil de l'homme moderne. Pris sous ce tour, Poe m'apparaît comme un Ilote qui veut faire rougir son maître. En fin, pour affirmer ma pensée d'une manière encore plus nette, Poe fut toujours grand, non seulement dans ses conceptions nobles, mais encore comme farceur. (Baudelaire 1976, 321)

La industrialización y el capitalismo nivelador aterra a los artistas; ya en 1800 Wordsworth afirma en Lyrical Ballads la superioridad del arte sobre la civilización, entendida como sinónimo de técnica, riqueza, progreso y ciencia. También en esta línea se expresa Shelley en su Defence of Poetry (1821), y más extremo es Coleridge en Constitution of Church and State (1837), proponiendo que los "artistas" formen un tribunal moral supremo de la comunidad, de modo que las gentes no se guíen únicamente por el beneficio y la utilidad. La metrópolis, como corazón de la "civilización", impone un anonimato y una indiferenciación que abruma especialmente a intelectuales y artistas, para quienes su nombre propio y su firma es esencial.

El artista moderno, sin embargo, concibe la metrópolis y la masa anónima unida a ella como un objeto artístico, un nuevo territorio inmenso y caótico por conquistar; el anonimato se convierte en lo sagrado para el lírico de la metrópolis. Baudelaire es el primero en entenderlo así y en mostrar una conciencia de que esta "nueva naturaleza" exige un sistema formal adecuado para su propia esencia, un método incompatible con la mimesis clásica. Baudelaire propuso una literatura urbana, e intuyó un nuevo público en las masas ciudadanas, con unas experiencias muy diferentes a las del campesino, el burgués o el aristócrata.

El paisaje urbano en Baudelaire no es, pues, un retrato mimético, y así lo entiende Antoine Compagnon, para quien " [...] les poèmes en prose du Spleen de Paris et, avant eux ou auprès d'eux, les poèmes en vers des 'Tableaux Parisiens' mettent l'accent moins sur le spectacle de la cité que sur la violence qu'elle exerce sur l'observateur lui-même, flâneur, homme des foules. Vers et prose rendent manifeste la perte de la subjectivité et de l'identité provoquée par la ville, par la vie modernes". (Compagnon, 116) 
Poe también concibió la metrópoli como espacio construido por la muchedumbre, una muchedumbre azarosa y caótica que le confiere su hálito vital; y junto a ella, la figura del observador, un individuo esencialmente ciudadano que mira desde dentro de la muchedumbre, fundido en ella. El siguiente fragmento del cuento de Poe "The Man of the Crowd", -de cuya traducción al francés se encargó Baudelaire- es muy revelador de esta fisonomía moderna -deforme y fantasmagórica de la multitud-, así como de una estrategia compositiva que se aleja de los dictados de la figuración realista:

All was dark yet splendid -as that ebony to which has been likened the style of Tertulian. The wild effects of the light enchained me to an examination of individual faces; and although the rapidity with which the world of light flitted before the window, prevented me from casting more than a glance upon each visage, still it seemed that, in my then peculiar mental state, I could frequently read, even in that brief interval of a glance, the history of long years. (Poe 1984, 392)

Baudelaire dio carta de naturaleza literaria a este hombre de la multitud, convirtiéndole en su famoso flaneur, pieza clave de su poética. El flaneur es ese paseante ocioso que se deja llevar por la masa y se embriaga de anonimato para llegar a captar el significado del instante fugitivo y transitorio, el único tiempo que Baudelaire considera digno de ser representado. Según Walter Benjamin, la descripción que Poe hace del flaneur está libre de la connivencia que Baudelaire le prestaba; en Poe el flaneur es ese que en su propia sociedad no se siente seguro, por eso busca la multitud. Poe difumina la diferencia entre el asocial y el flaneur. (Benjamin, 64).

Benjamin entiende que la indolencia del flaneur es solamente aparente, tras ella se oculta una actitud vigilante y observadora que le convierte en detective a su pesar. Disfruta de su incógnito, observa la multitud desde dentro sin llegar a pertenecer a ella. El flaneur se sueña cercano al artista; "Todo el mundo alaba el lápiz veloz del dibujante. Balzac quiere que la maestría artística esté en general ligada al captar rápido" (Benjamin, 55-6). Y es que el artista de la vida moderna es el intérprete de las masas, las dota de una significación efímera y cambiante, instantánea y constante.

Pero esta figura del curioso que observa sin ser visto, que en Poe se reduce a un elemento argumental y a un principio de teoría compositiva, en Baudelaire se convierte en la clave de su método poético, pues parte esencial de la modernidad de Baudelaire está en su propuesta de la desaparición del autor; Baudelaire rompe por primera vez con la idea de que el autor -el hombre, el sujeto empírico- es fundamental a la hora de enjuiciar sus escritos, e insiste en que cualquier huella per- 
sonal del artista en la obra ha de ser eliminada. Que este postulado se plasma en su método poético lo explica Walter Benjamin así:

Detrás de las máscaras que usaba, el poeta que fue Baudelaire guardaba incógnito. Podía parecer muy provocativo en el trato; en su obra procedía muy circunspectamente. El incógnito es la ley de su poesía. La estructura de su verso es equiparable al plano de una gran ciudad en la que nos movemos sin ser notados, encubiertos por bloques de casas, por pasos a través de puertas o patios. En ese plano se les designa a las palabras su sitio exacto, como a conjurados antes de que estalle la revuelta. Baudelaire conspira con el lenguaje mismo. Calcula sus efectos paso a paso. (ibid, 117)

La única huella que el autor ha de dejar está en el lenguaje y en el método compositivo con que construye la obra. Esta idea, que fue introducida por Poe, como ya se ha dicho más arriba, es reformulada por Baudelaire y convertida en una teoría estética que ha marcado la evolución de las artes hasta nuestros días. De hecho, si hay dos obras que han influido decisivamente en la sensibilidad artística y en la retórica de Baudelaire estas son los ensayos Philosophy of Composition (1845) y The Poetic Principle (1850) de Poe; parte de la primera fue traducida por él y publicada en La Revue francaise en 1859 bajo el título Genèse d'un Poème, convirtiéndose en un texto fundamental en la poética Baudelaireana. A través de estos textos Baudelaire descubre tales afinidades estéticas con Poe que se puede decir que casi lo asimila, haciendo suyos conceptos estéticos que repetirá a menudo en sus ensayos.

El artista ya no es un inspirado, como lo soñaron los románticos, ni un sabio ni un moralista, como querían los clásicos, sino un poeta. El artista quiere conquistar un territorio autónomo, escapando a las imposiciones de la moral, de la filosofía y de la historia. La obra de arte debe ser justificación única y exclusiva de sí misma. Es Poe el que formula por primera vez el concepto de Art for art's sake en su ensayo "The Poetic Principle" en 1831, aunque este principio se consolidó unos años más tarde en su versión francesa de lart pour l'art.

La "desaparición" del autor propicia un ensimismamiento del lenguaje poético, y la poesía adquiere un grado importante de independencia. Baudelaire, siguiendo a Poe, exige que el poema sea juzgado por la coherencia entre sus presupuestos teóricos y la realización técnica, planteando así un razonamiento que no ha abandonado ya nunca el mundo del arte. Como afirma Juan Carlos Orejudo, Baudelaire rechaza el didactismo en el arte a instancias de Poe:

Para Baudelaire, la peor poesía es la que trata de expresar ideas extrañas al arte, ideas científicas o políticas, lo cual implica el descuido de la forma en provecho de la claridad y del poder de la idea. La separación entre la forma y el contenido es lo 
que, según Baudelaire produce el aniquilamiento de la poesía. Ésta no debe ser sometida a nada exterior que debilite su autonomía o su autosuficiencia. (Orejudo Pedrosa, 179)

A pesar de que América no supiera ver en su momento la importancia de Poe y la modernidad de sus planteamientos, sus méritos le han sido reconocidos con posterioridad. Nadie como William Carlos Williams ha destacado su papel precursor dentro de toda una tradición literaria norteamericana; como éste afirmó en In the American Grain:

On him is FOUNDED A LITERATURE -typical; an anger to sweep out the unoriginal, that became ill-tempered, a monomaniacal driving to destroy, to annihilate the copied, the slavish, the FALSE literature about him: this is the major impulse in his notes -darkening as he goes, losing the battle, as he feels himself going under- he emerges as the ghoulish, the driven back. It is the crudeness with which he was attacked in his own person, scoffed at-

He declares, maintains himself, presupposes himself and is first rate. FIRST! -madly, valiantly battling for the right to be first -to hold up his ORIGINALITY-. (Williams, 223)

"Originalidad" tiene para Williams un doble sentido, el de creatividad y el de "origen", entendido como lugar de procedencia; aunque usa la palabra indistintamente, predomina en su ensayo la segunda acepción, pues Williams quiere resaltar el profundo carácter americano de la obra de Poe. La modernidad de éste es consecuencia tanto de su tiempo como de su lugar, y su grandeza estriba, según Williams, en el hecho de que Poe:

"[...] turned his back and faced inland, to originality, with the identical gesture of a Boone. [...] Thus Poe must suffer by his originality. Invent that which is new, even if it be made of pine from your own yard, and there's none to know what you have done. [...] Here Poe emerges -in no sense the bizarre, isolate writer, the curious literary figure. On the contrary, in him American Literature is anchored, in him alone, on solid ground. (Ibíd., 226)

Poe ofreció un modelo para aquellos que deseaban romper con los dictados del naturalismo, y Baudelaire supo apreciar prematuramente la modernidad del americano, convirtiéndole en el eje de una importante reconceptualización de la noción de artista; Poe y Baudelaire abrieron las puertas a cien años de futuro artístico. 


\section{Obras citadas}

ASSELINAU, Charles. Charles Baudelaire, su vida y su obra (traducción y notas de Pere Rovira del original Charles Baudelaire, sa vie et ses ouvrages). Valencia: Pre-textos, 2004.

BAUDELAIRE, Charles. Oeuvres Complètes. Paris: Gallimard, 1976.

BENJAMIN, Walter. Iluminaciones II: Baudelaire (Prólogo y traducción de Jesús Aguirre). Madrid: Taurus, 1972.

COMPAGNON, Antoine. Baudelaire:devant l'innombrable. Paris: Presses de l'Université de Paris-Sorbonne, 2003.

OREJUDO PEDROSA, Juan Carlos. Los caminos de la poesía y de la crítica en Baudelaire. Madrid: Ediciones de la Universidad Autónoma de Madrid, 2005. POE, Edgar Allan. Poetry and Tales. New York: The Library of America, 1984.

WALKER, I.M. Edgar Allan Poe: the Critical Heritage. London \& New York: Routledge, 1986.

WILLIAMS, William Carlos. In the American Grain. London: MacGibbon \& Kee, 1966. 